\title{
Red meat consumption and type 2 diabetes: a systematic review of the evidence
}

\author{
E.J. Derbyshire ${ }^{1}$ and C.H.S. Ruxton ${ }^{2}$ \\ ${ }^{1}$ Freelance Nutritionist, Nutritional Insight Ltd, 65 Mayfair Avenue, Surrey, KT4 7SJ and ${ }^{2}$ Freelance Dietitian, \\ Nutrition Communications, 26 East Road, Cupar, KY15 4HQ
}

Lean red meat in moderation can provide an array of nutrients, without substantially increasing intakes of energy and saturated fatty acids ${ }^{(1)}$. Nevertheless, there have been concerns that red meat consumption may be associated with risk of type 2 Diabetes Mellitus $(\mathrm{T} 2 \mathrm{DM})^{(2)}$, although there are discrepancies between individual study findings. The present systematic review investigated the overall the evidence in relation to whether meat consumption is convincingly associated with T2DM risk ${ }^{(3)}$.

The Preferred Reporting Items for Systematic Reviews and Meta-Analyses (PRISMA) guidelines were applied to identify evidence published between 2004 and 2014. Application of these guidelines located 21 epidemiological and two clinical studies.

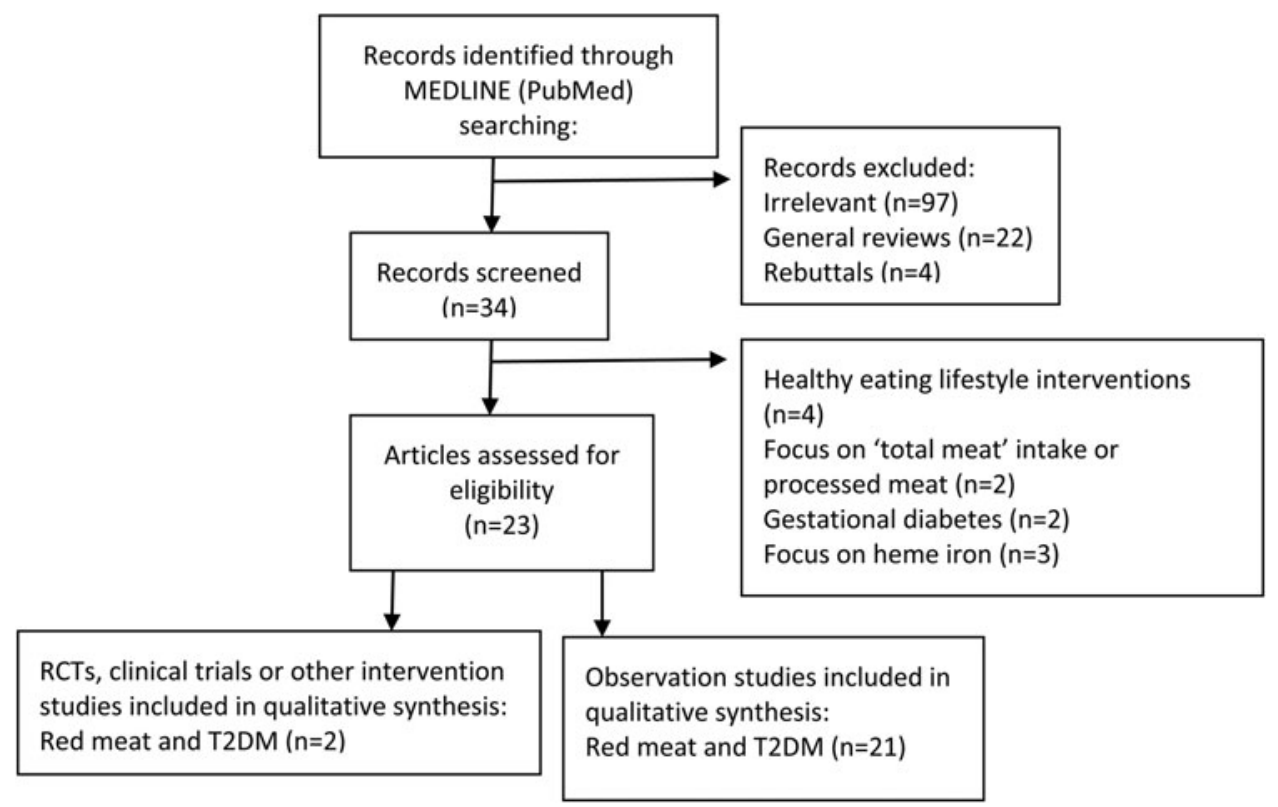

Key: RCT, randomised controlled trial; T2DM, type 2 diabetes mellitus.

Collated evidence suggested that the T2DM risk was much weaker and inconsistent for lean red meat, with associations tending to become non-significant after accounting for body weight parameters. Where studies considered high intakes in relation to T2DM risk, associations were evident at intakes $>600 \mathrm{~g}$ per week which is greater than UK mean intakes. There was no agreement about likely mechanisms linking red meat with T2DM risk raising the possibility that associations may be spurious.

While more trials are needed to determine whether or not red meat consumption affects markers of glycaemic control, an appropriate response may be to keep red meat intakes within the guidelines of $\leqslant 500 \mathrm{~g}$ per week, while opting for lean cuts or trimming off fat.

This review was funded by the Meat Advisory Panel which is supported by an unrestricted grant from BPEX and EBLEX, divisions of the Agriculture and Horticulture Development Board (AHDB). The views expressed in this paper are those of the authors alone. For further information, see www.meatandhealth.com

1. Ruxton CHS, Derbyshire EJ \& Pickard RS (2012) Nutrition Bulletin 38(2), 178-190.

2. Feskens EJ, Sluik D \& van Woudenbergh GJ (2013) Curr Diab Rep 12(2), 298-306.

3. Derbyshire EJ \& Ruxton CHS (2015) Nutrition \& Food Science. In press. 